\title{
Strategies for the Prevention of Microbial Biofilm Formation on Silicone Rubber Voice Prostheses
}

\author{
Lígia Rodrigues, ${ }^{1}$ Ibrahim M. Banat, ${ }^{2}$ José Teixeira, ${ }^{1}$ Rosário Oliveira ${ }^{1}$ \\ ${ }^{1}$ Centro de Engenharia Biológica, Universidade do Minho, Campus de Gualtar, 4710-057 Braga, Portugal \\ ${ }^{2}$ School of Biomedical Sciences, University of Ulster, Coleraine BT52 1SA, Northern Ireland, United Kingdom
}

Received 22 March 2006; revised 12 June 2006; accepted 19 June 2006

Published online 4 October 2006 in Wiley InterScience (www.interscience.wiley.com). DOI: 10.1002/jbm.b.30673

\begin{abstract}
Total laryngectomy, a surgical treatment for extensive cancer of larynx, which alters swallowing and respiration in patients, is followed up with a surgical voice restoration procedure comprising tracheoesophageal puncture techniques with insertion of a "voice prosthesis" to improve successful voice rehabilitation. However, microbial colonization is a major drawback of these devices. Antimicrobials are usually used to prevent the colonization of silicone rubber voice prostheses by microorganisms. However, long-term medication induces the development of resistant strains with all associated risks and the development of alternative prophylactic and therapeutic agents, including probiotics and biosurfactants, have been suggested. The inhibition of microbial growth on surfaces can also be achieved by several other techniques involving the modification of physicochemical properties of the biomaterial surface or the covalently binding of antimicrobial agents to the biomaterial surface. An overview of the different approaches investigated to date and future perspectives to reduce the frequent replacements of voice prostheses in laryngectomized patients through microbial biofilm retardation is presented and discussed. (C) 2006 Wiley Periodicals, Inc. J Biomed Mater Res Part B: Appl Biomater 81B: 358-370, 2007
\end{abstract}

Keywords: voice prosthesis; biofilm; prophylactic treatment; surface modifications; biosurfactants

\section{INTRODUCTION}

Different methods of rehabilitating the lost voice of laryngectomized patients have been developed as the inability to speak is the most disabling consequence of total laryngectomy. The main procedure for speech rehabilitation of patients is the insertion of silicone rubber voice prosthesis in a surgically created tracheoesophageal fistula. Since the introduction of the first reliable voice prosthesis by Singer and Blom in 1980, the success rate of vocal rehabilitation after total laryngectomy has improved considerably. ${ }^{1,2}$ There are different types of voice prostheses: nonindwelling (removable) devices, which have to be removed regularly for cleaning purposes, such as the Blom and Singer ${ }^{1}$ and Panje, ${ }^{3}$ and the indwelling devices, which remain in the stand for a longer period of time, such as the Groningen button, ${ }^{4}$ Traissac et al., ${ }^{5}$ Nijdam et al., ${ }^{6}$ Provox ${ }^{\circledR 7}$ and Staffieri and Staffieri. ${ }^{8}$ Indwelling voice prostheses are generally preferred by laryngectomees, as many patients are inept due to lack of manual dexterity or reluc-

Correspondence to: L. Rodrigues (e-mail: lrmr@deb.uminho.pt)

Contract grant sponsor: FCT (Fundação para a Ciência e a Tecnologia); Contract grant numbers: SFRH/BPD/26064/2005

(C) 2006 Wiley Periodicals, Inc. tance to handle the prosthesis. Therefore, nonindwelling voice prostheses are especially allocated to motivated patients willing to be autonomous. Moreover, in the United States, for example where health service is expensive and patients have to overcome large distances to reach a laryngologist, nonindwelling voice prostheses are more frequently used than in Western Europe.

The self-retaining low resistance Provox voice prosthesis, developed in the Netherlands Cancer Institute in $1988^{9}$ together with the Groningen button voice prosthesis are the most commonly used devices in Europe at present. Table I summarizes a comparison of the features, advantages, and disadvantages for the most common Dutch voice prostheses.

All indwelling silicone rubber voice prostheses suffer from microbial biofilm formation along the time, leading to dysfunction and, eventually, replacement. Therefore, microbial colonization and biofilm formation have been reported to lead to salivary leakage through the prosthesis valve, salivary leakage around the prosthesis, deterioration of the prosthesis, and increased airflow resistance due to valve mechanism blocking. ${ }^{10,12}$

The aim of this paper is to review the current knowledge on such biofilm formation and the different approaches developed so far to inhibit or minimize its formation 
PREVENTION OF BIOFILM FORMATION ON VOICE PROSTHESES

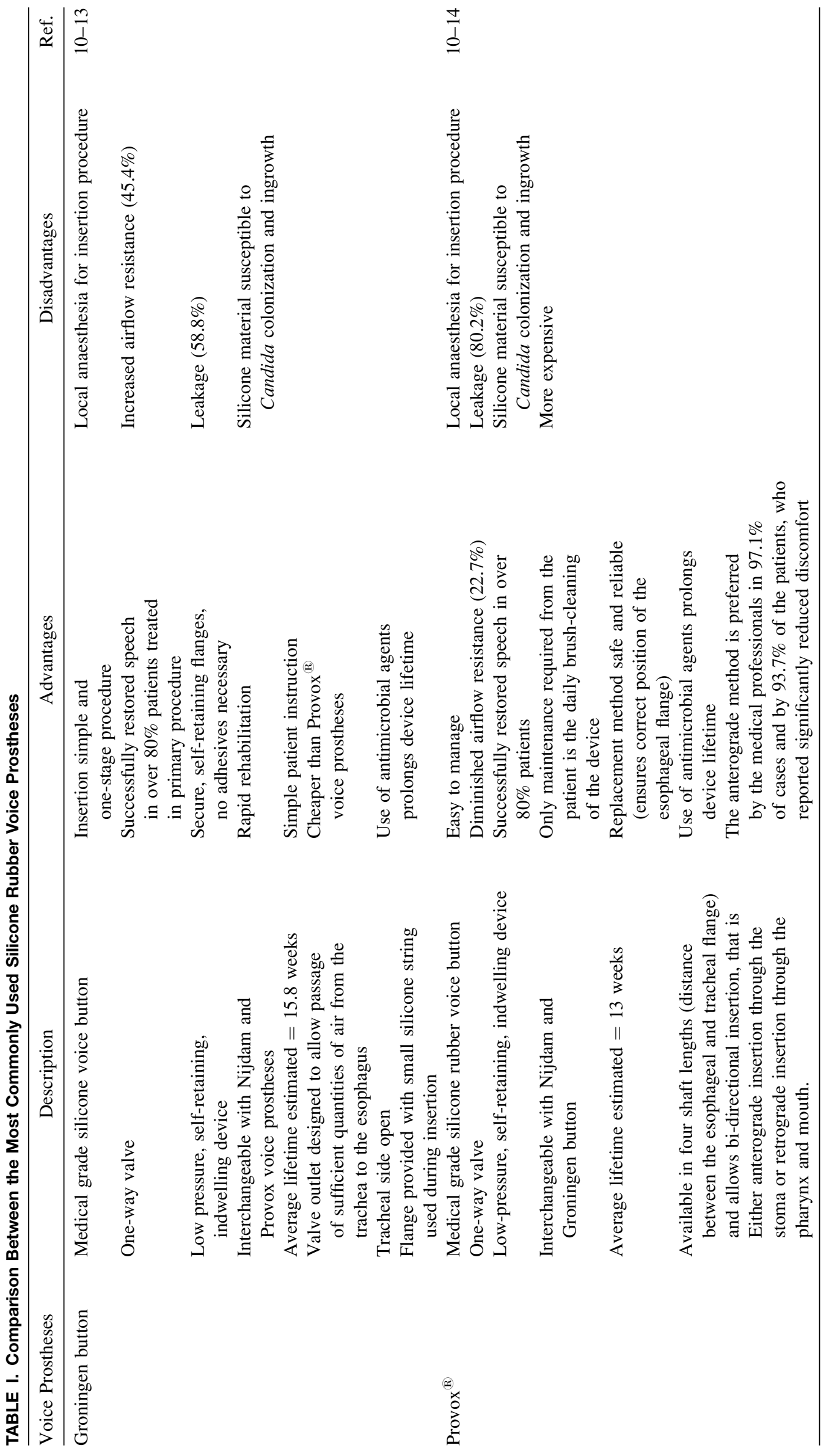


through interference with microbial adhesion, growth, or survival.

\section{BIOFILM FORMATION ON VOICE PROSTHESES}

Several strategies seem useful to prevent biofilm formation on voice prostheses. In general, the main goal is to modify the physicochemical properties of the surface in order to reduce the force of attraction between microorganisms and the surface of the biomaterial. For example, bacterial adhesion on highly negatively charged biomaterials is low. ${ }^{15}$ Keogh and Eaton ${ }^{16}$ have shown that albumin and heparin coatings decrease the adhesiveness of biomaterials. However, microorganisms always seem to be able to adhere to some extent to solid materials. Moreover, when proteins are present they can cover an antiadhesive biomaterial and become the anchors for the adhesion of microorganisms.

Another approach to prevent biofilm formation is to inhibit the growth of the adhering microorganisms. This can be achieved through the design of antibiotic releasing biomaterials. A disadvantage of such an application is that it only works for a few days to weeks, as the amount of antibiotic that is actually released is limited and does not exceed $15 \%$ of the total amount incorporated. ${ }^{17}$ Moreover, there is a serious problem with antibiotic releasing materials, namely related to the low dose actually released, which leads to the development of antibiotic resistant microbial strains. ${ }^{18}$ Also, the use of new techniques for covalently binding an active antimicrobial agent onto the biomaterial surface has been reported as alternative. For example, polymers with incorporated quaternary ammonium groups have shown such antimicrobial activity in vitro. ${ }^{19-21}$

\section{Characteristics of Biofilms on Silicone Rubber Voice Prostheses}

Microorganisms can colonize on surfaces of biomedical devices in vivo, resulting in damage of the devices and sometimes in infection. Voice prostheses are nonimplanted devices in contact with the open air, thus in a nonsterile environment and consequently prone to microbial colonization. Voice prostheses are mainly made of medical grade silicone rubber because of its excellent mechanical and moulding properties. Although silicone rubber has long been considered as an inert biomaterial, this notion has been questioned ${ }^{22}$ because of the problems arising with silicone-filled breast implants. Since then, it has been established that silicone rubber devices have the tendency to become quickly colonized by microorganisms, ${ }^{23,24}$ most notably Candida species, ${ }^{25-29}$ resulting for example in frequent replacement of indwelling voice prostheses. ${ }^{10,27,30}$

$\mathrm{Neu}$ et al. $^{24}$ studied the biodeterioration of medicalgrade silicone used for voice prostheses. The yeasts in the mixed biofilm formed on the prostheses were found to be directly responsible for the material defects. The same authors $^{27}$ also investigated the taxonomy of the microflora on explanted silicone rubber voice prostheses and reported that most of the bacteria were mainly streptococci and the yeasts were mainly Candida species.

Van der Mei et al. ${ }^{31}$ carried out an electron microscopy investigation for the ingrowth features as seen in vivo for Candida strains using a modified Robbins device. The onset of the ingrowth features observed in vivo were shown by all strains: sometimes in the form of a small group of yeasts growing into a hole-like defect or, at other times, in the form of clearly visible imprints on the silicone rubber, left after detachment of adhering yeasts during preparation of the samples for electron microscopy. Although Candida species are believed to be responsible for microbial overgrowth on the voice prostheses, the role of bacteria has also been emphasized. ${ }^{30,32-35}$

Ell et al. ${ }^{32}$ studied the microflora of 55 failed Groningen buttons. In those where valve failure occurred due to leakage $(n=25)$, there was a positive correlation between biofouling in the lumen of the valve and the number of streptococci cultured. In valves failing due to increased air flow resistance, enterococci were particularly found on the esophageal side of the voice prostheses. In another study, Van Weissenbruch et al. ${ }^{30}$ identified 14 different yeast species in association with other commensals of the oral flora. The yeast strains were the most distinctive colonizers of the prostheses representing $72.9 \%$ of the total number of microorganisms, among which Candida albicans and Candida glabrata were predominant. Staphylococcus aureus was also found to be another predominant microorganism in all cultures and it was often isolated in association with Candida strains. $^{30,34}$ Others, such as Rothia dentocariosa, have been suggested as causative organisms for prosthesis failure by Elving et al. ${ }^{36,37}$ Only $R$. dentocariosa and $S$. aureus appear to positively influence adhesion to silicone rubber of yeast species from saliva, especially of $C$. albicans. $^{35}$ Interestingly, this observation coincides with clinical findings that the malfunctioning of silicone rubber voice prostheses occurs more rapidly when either $R$. dentocariosa or $S$. aureus are present in the biofilm in combination with $C$. albicans, a form of positive synergistic interactive relationship.

\section{MODIFICATIONS OF SILICONE RUBBER SURFACES}

Voice prostheses are continuously exposed to saliva, food, and drinks that together with the oropharyngeal microflora contribute to valve failure and frequent exchange of the implant. $^{25}$ Therefore, the antifouling improvement of the silicone rubber material is desirable. In case of laryngectomized patients with voice prostheses (average lifetimes less than two months) it is necessary to employ "antibiofilm" therapy from the time of insertion of the prostheses, preferably without using antimycotics or antibiotics due to the risk of inducing resistant strains. ${ }^{38,39}$ Different approaches have been undertaken to modify the silicone 
PREVENTION OF BIOFILM FORMATION ON VOICE PROSTHESES

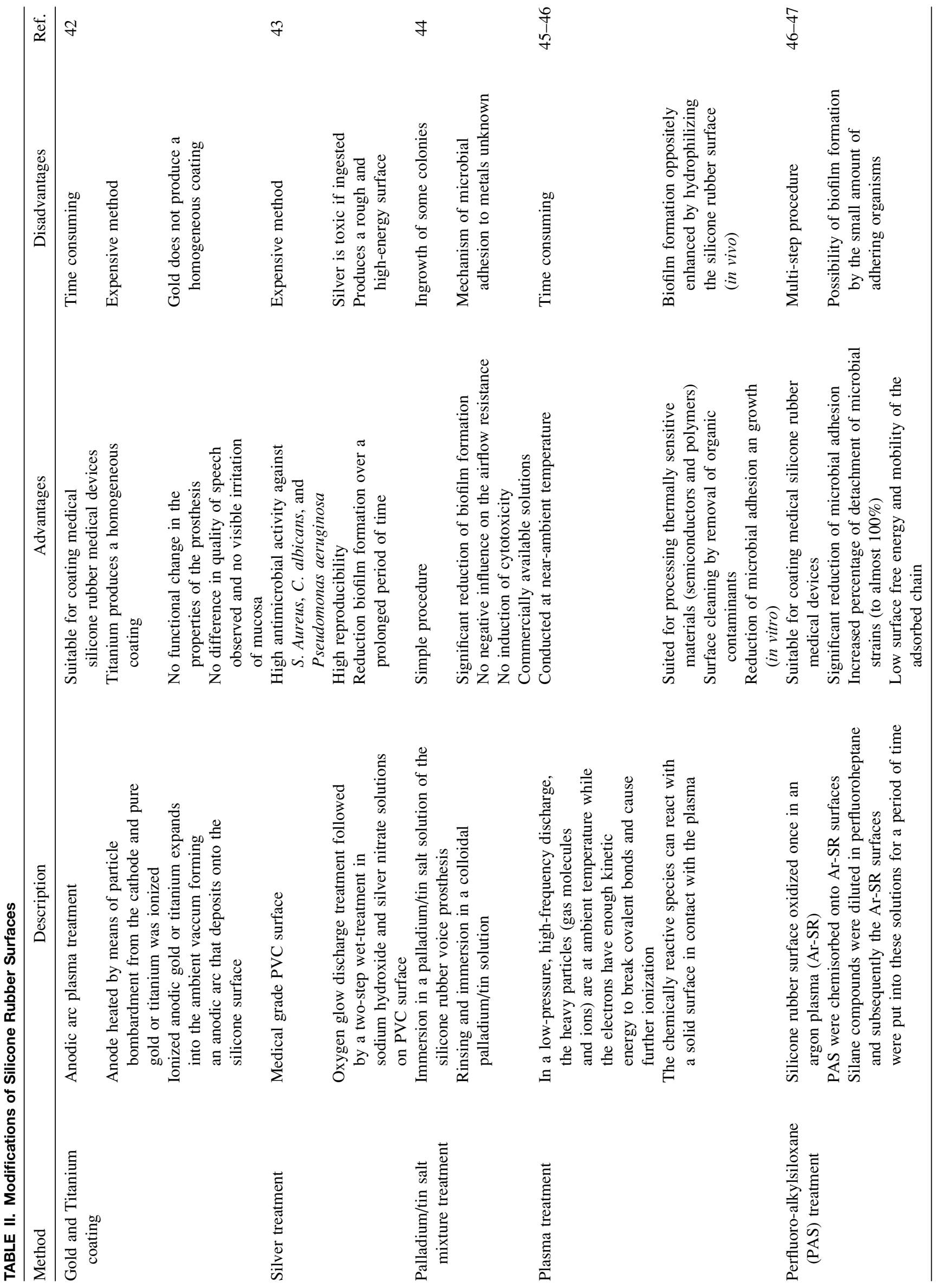

Journal of Biomedical Materials Research Part B: Applied Biomaterials DOI $10.1002 / \mathrm{jbmb}$ 


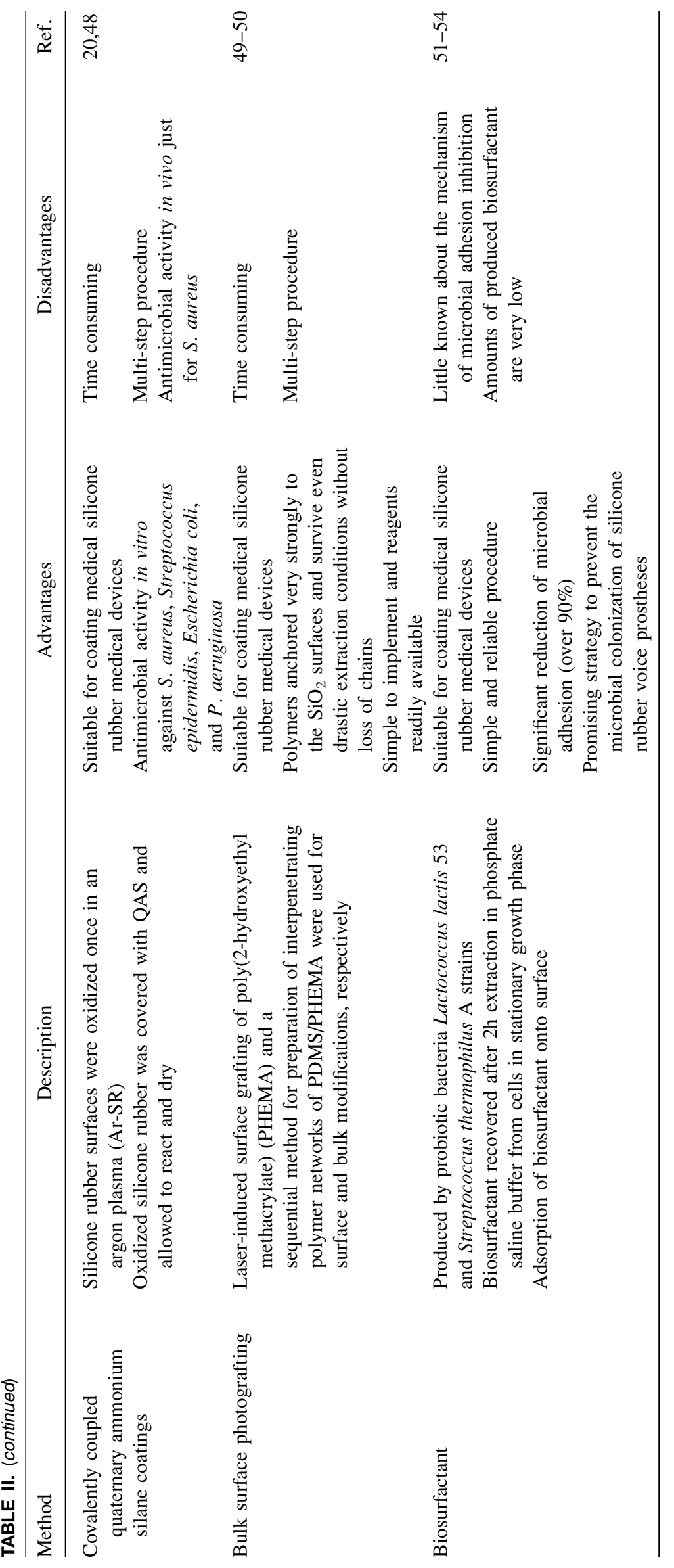


rubber surface as an obvious strategy to inhibit biofilm formation and consequently to prolong the lifetime of voice prostheses. Although voice prostheses will become covered by a conditioning film of adsorbed salivary components prior to adhesion of bacteria or yeasts, experiments in the human oral cavity have demonstrated that the properties of this conditioning film are determined by the material itself. $^{40,41}$ As a consequence, biofilm formation can be influenced by adjusting the properties of the voice prostheses material or by surface modification.

A brief description of several methods used for silicone rubber surface modifications is listed in Table II.

\section{Metal Coating Techniques}

Arweiler-Harbeck et al. $^{42}$ aimed at creating a Candidaresistant surface by either gold or titanium coating of silicone voice prostheses using a new method of surface modification by anodic vacuum arc coating. Although no functional change in the properties of the prostheses and no difference in the quality of speech were reported by patients as a result of metal coating, further studies are needed to show that metal coating with gold or titanium lead to a retardation of Candida growth.

Balazs et al. $^{43}$ reported that silver impregnation of polyvinyl chloride completely inhibited $P$. aeruginosa adhesion and efficiently prevented colonization over a longer period. However, despite the high antimicrobial activity of silver coatings, silver is toxic if ingested, which is an obvious drawback as a voice prosthesis is nothing more than a tracheoesophageal shunt. Furthermore, silver produces a rough, high-energy surface, which can promote plaque formation and maturation. ${ }^{55}$

Dijk et al. ${ }^{44}$ treated Groningen button voice prostheses with a colloidal palladium/tin solution to form a thin metal coat and showed significant biofilm reduction on the heavily palladium/tin-treated prostheses in comparision to the untreated prostheses. Therefore, palladium/tin-treated silicone rubber may potentially extend the lifetime of indwelling voice prostheses.

\section{Plasma Surface Treatment Technique}

Polymeric surfaces can be efficiently modified by a glowdischarge plasma treatment, in which a nonpolymer forming plasma (i.e. plasma of argon, oxygen or nitrogen) is used. Plasma treatment essentially modifies the composition and structure of a few molecular layers at or near the surface of the material without affecting the bulk properties. ${ }^{49}$

Everaert et al. $^{45}$ investigated the effects of repeated argon plasma treatment of medical grade hydrophobic silicone rubber on in vitro adhesion and growth of selected bacteria and yeasts isolated from voice prostheses, as well as in vivo biofilm formation. The results obtained for in vivo experiments showed a reduction in microbial adhesion and growth on silicone rubber. However, in vivo biofilm formation on silicone rubber voice prostheses was oppositely enhanced by hydrophilizing the silicone rubber surface. Several reasons may explain such contradictory results for in vitro and in vivo evaluation of the fouling properties including the wide variability of strains occurring in vivo, the different cell surface properties, and the coadhesion phenomena between bacteria or yeasts in vivo, which make in vitro evaluations difficult. Finally, the conditions in the oropharyngeal cavity (in vivo) are highly dynamic with regard to nutrient availability, temperature, humidity, and shear forces.

\section{Perfluoro-Alkylsiloxane Surface Treatment}

Everaert et al. ${ }^{45}$ demonstrated that biofilm formation on voice prostheses surfaces in vivo is governed by substratum hydrophobicity. Therefore, the improved antifouling performance of voice prostheses may be achieved through increasing the hydrophobicity of the silicone rubber such as by adsorption of fluorocarbons (Teflon) to the surface. Fluorocarbon surfaces are slightly more hydrophobic than silicone rubber and were reported to hardly attract any dental plaque during nine days of exposure to the dynamic conditions of the human oral cavity. ${ }^{56}$ Additionally, the same authors ${ }^{46}$ prepared reactive surfaces by argon plasma glow discharge prior to anchoring fluoro-alkyltrichlorosilanes. A promising aspect of chemisorbed long chain fluoro-alkylsiloxanes to silicone rubber is that they were found to reduce microbial adhesion and to increase the percentage of detachment of adhering microorganisms. Finally, these authors ${ }^{47}$ also reported significant reductions over an evaluation period of approximately two to eight weeks when using chemisorption of long (8 fluorocarbon units) perfluoro-alkylsiloxane (PA) polymer chains due to the high hydrophobicity and mobility of these chains.

\section{Covalently Coupled Quaternary Ammonium Silane Coatings}

Another possible strategy to prevent voice prostheses microbial colonization is by functionalization of the silicone rubber surface with quaternary ammonium groups, widely known as antimicrobial agents (disinfectants). Poly(methacrylates) with methyl or ethyl quaternary ammonium chloride side groups showed antimicrobial activity ${ }^{48,57,58}$ against Gram-negative strains, although Gram-positive staphylococci were little affected by these polymers.

Gottenbos et al. ${ }^{20}$ determined the antimicrobial activity of 3-(trimethoxysilyl)-propyldimethyloctadecylammonium chloride (QAS) coating on silicone rubber. Antimicrobial activity of QAS-coated silicone rubber was demonstrated both in vitro and in vivo. The application of positively charged biomaterial surfaces to prevent infection is unusual as current research has been mainly focused on designing nonadhesive surfaces. Positively charged surfaces are strongly adhesive to the negatively charged bacteria; however, the positive charge inhibited biofilm progression from the initial adhesion stage toward growth stage since immobilized QAS 
molecules interact with the cell membranes of adhering bacteria, presumably causing membrane leakage and cell death.

\section{Bulk Surface Modification Techniques}

Bulk surface modification methods can be achieved through blending, copolymerization, interpenetrating polymer networks, and functionalization. Among these mentioned bulk modification techniques, laser-induced surface grafting and sequential method for interpenetrating polymer network preparation have the potential for local modification of a specific section on a polymeric sample.

A simple procedure for synthesizing dense and homogeneous poly(methyl methacrylate) brushes on silicon substrates is by atom-transfer radical polymerization process starting from self-assemble monolayers of covalently anchored initiators as described by Ramakrishnan et al.$^{50} \mathrm{An}$ advantage of the system described in comparison to similar systems on gold surfaces is that the polymers are anchored very strongly to the $\mathrm{SiO}_{2}$ surfaces and survive even drastic extraction conditions without loss of chains, thus enabling its use in biomedical applications.

\section{The Use of Surface Active Molecules (Biosurfactants)}

Biosurfactants are microbial amphiphilic and polyphilic polymers that tend to interact with the phase boundary between two phases in a heterogeneous system, defined as interface, interfering with the microbial adhesion and detachment process. Biosurfactants may be oriented in different ways at the microbial cell surface. However, regardless of their orientation, if they are released from the cell surface or excreted into the area between the cell surface and interface, they will probably lead to detachment of bacteria from the interface.

Biosurfactants have become an important biotechnological product for industrial and medical applications. ${ }^{59,60}$ Their popularity as high value microbial products is related to their specific action, low toxicity, relative ease of preparation, and widespread applicability. ${ }^{61}$ They can be used as emulsifiers, de-emulsifiers, wetting agents, spreading agents, foaming agents, functional food ingredients, and detergents in various industrial sectors. ${ }^{62}$ Several studies concerning the applications, production methods, and characterization of biosurfactants are described in the literature. ${ }^{63,64}$

The role of biosurfactants as defense weapons in postadhesion competition with other strains or species has been suggested for biosurfactants released by Streptococcus mitis strains against Streptococcus mutans adhesion. ${ }^{65-67}$ Studies have also shown that certain strains of bacteria, such as Lactobacillus strains, commonly found in healthy urogenital microflora, can protect the host against infection by inhibiting uropathogens ${ }^{68-70}$ and biosurfactant production is one of the mechanisms by which they are speculated to achieve this. ${ }^{67,71}$ Velraeds et al. ${ }^{67,72}$ determined the role of these biosurfactants as anti-adhesive, nonantibiotic coatings on catheter surfaces. However, only one pathogen (E. faecalis) was studied and various degrees of inhibition were observed with the various Lactobacillus strains. Therefore, it should not be expected that biosurfactants of different Lactobacillus strains will produce equivalent results for any given pathogen.

Another well-known group of biosurfactant producers are $S$. thermophilus strains isolated from heat exchanger plates in the dairy industry. ${ }^{73}$ Busscher et al. ${ }^{51}$ examined whether biosurfactant release by $S$. thermophilus might prolong the lifetime of indwelling silicone rubber voice prostheses. To this end, the adhesion of different yeast strains, isolated from Groningen button voice prostheses, to silicone rubber in the presence and absence of biosurfactantreleasing S. thermophilus B cells was studied. The results obtained provide evidence in support of the belief among laryngectomized patients and some ear-nose-throat clinicians that dairy products containing active bacteria may prolong the lifetime of indwelling silicone rubber voice prostheses. A later study extended into microbial growth phase also indicated a positive effect of the biosurfactant released by streptococci on biofilm formation. ${ }^{52}$

Recently, we investigated the effect of biosurfactants obtained from probiotic bacteria, L. lactis 53 and S. thermophilus A, and also a rhamnolipid obtained from P. aeruginosa DS10-129, on the adhesion of microbial strains isolated from explanted voice prostheses to silicone rubber with and without an adsorbed biosurfactant layer in a parallel plate flow chamber. ${ }^{53,74,75}$ The results obtained showed that the biosurfactants obtained from probiotic bacteria were more effective in decreasing both the initial deposition rates and the number of microorganisms adhering after $4 \mathrm{~h}$ for all microorganisms, as compared to the rhamnolipid. The biosurfactant obtained from L. lactis 53 was effective in decreasing the initial deposition rates of $S$. epidermidis GB 9/6, Streptococcus salivarius GB 24/9, and S. aureus GB $2 / 1$, allowing for a $90 \%$ reduction of the deposition rates ( $\mathrm{j}_{0}$, Figure 1$)$. The deposition rates of $R$. dentocariosa GBJ 52/2B, C. albicans GBJ 13/4A, and C. tropicalis GB $9 / 9$ were far less reduced than other strains tested. Interestingly, the biosurfactant from S. thermophilus A was more effective in decreasing the initial deposition rate of $R$. dentocariosa GBJ 52/2B, which is one of the bacterial strains commonly associated with premature voice prostheses failure. Both biosurfactants reduced the numbers of microorganisms adhering to silicone rubber after $4 \mathrm{~h}$ by approximately $90 \%\left(\mathrm{n}_{4 \mathrm{~h}}\right.$, Figure 2 ), except for C. albicans GBJ 13/4A, C. tropicalis GB 9/9 and R. dentocariosa GBJ 52/2B that showed less reductions ranging between 56 and $70 \%$. Further work was developed ${ }^{54}$ to assess the influence of these biosurfactants in the biofilm formation on voice prostheses (Figure 3). Both biosurfactants greatly reduced microbial numbers on prostheses and also induced a reduction in the airflow resistance of voice prostheses after biofilm formation. The use of biosurfactants obtained from probiotic bacteria may represent a promising strategy to prevent microbial colonization of silicone rubber voice prostheses, thus prolonging their lifetime. 


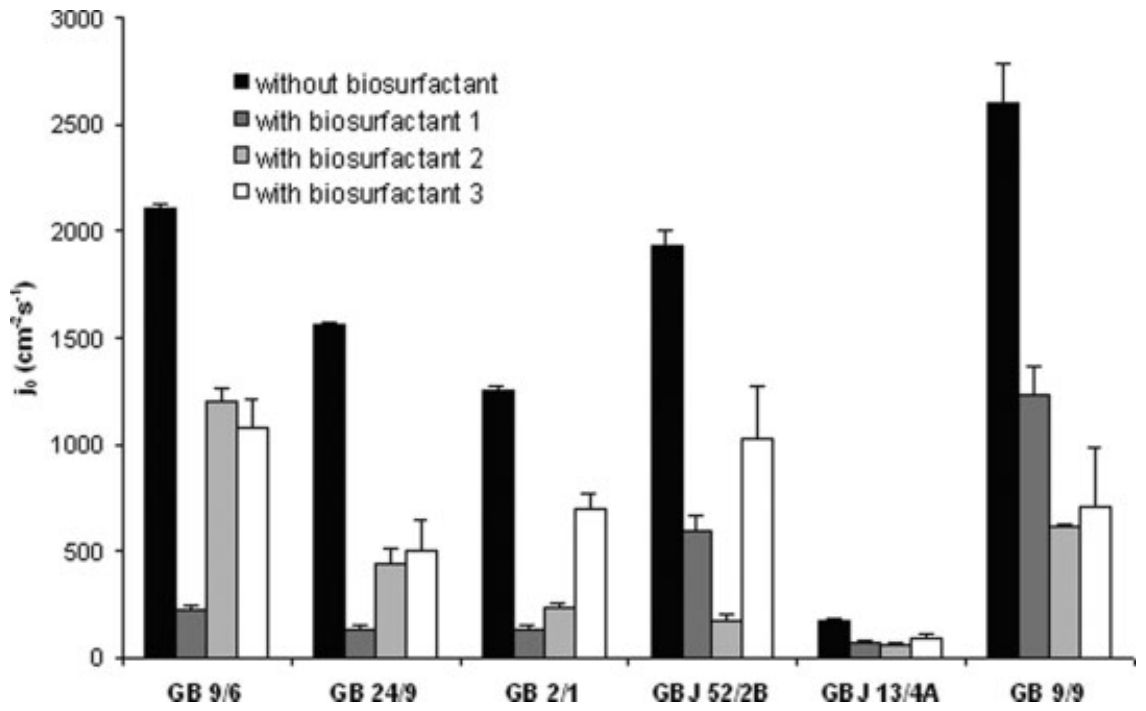

Figure 1. The initial deposition rates $\left(j_{0}\right)$ of the bacterial strains (Staphylococcus epidermidis GB $9 / 6$, Streptococcus salivarius GB 24/9, Staphylococcus aureus GB 2/1, and Rothia dentocariosa GBJ 52/ 2B) and yeast (Candida albicans GBJ 13/4A and Candida tropicalis GB 9/9) isolated from explanted voice prostheses on silicone rubber with and without an adsorbed biosurfactant layer. Biosurfactant 1,2 , and 3 were obtained from L. lactis 53, S. thermophilus A, and P. aeruginosa DS10-129, respectively. Results are averages of triplicate experiments varying within 10-15\% (ANOVA) and the standard deviation represented by error bars. Adapted from Rodrigues et al. ${ }^{53,74,75}$

\section{PROPHYLATIC TREATMENT ON SILICONE RUBBER VOICE PROSTHESES}

It is well-known that biofilms are resistant to a range of antifungal agents currently in clinical use, including amphotericin $\mathrm{B}$ and fluconazole, and there appear to be multiple resistance mechanisms and thus alternative prophylactic treatments are being explored to prolong voice prostheses lifetime.

\section{The Use of Probiotics}

As antimicrobial resistance is becoming a source of concern in modern medicine and health-improving functional foods are gaining in popularity, the development of alternative prophylactic and therapeutic agents, including probiotics, has been investigated. ${ }^{76}$ Lactobacilli are one of the most well-known probiotic bacterial genera and play an important role in the maintenance of a healthy intestinal and

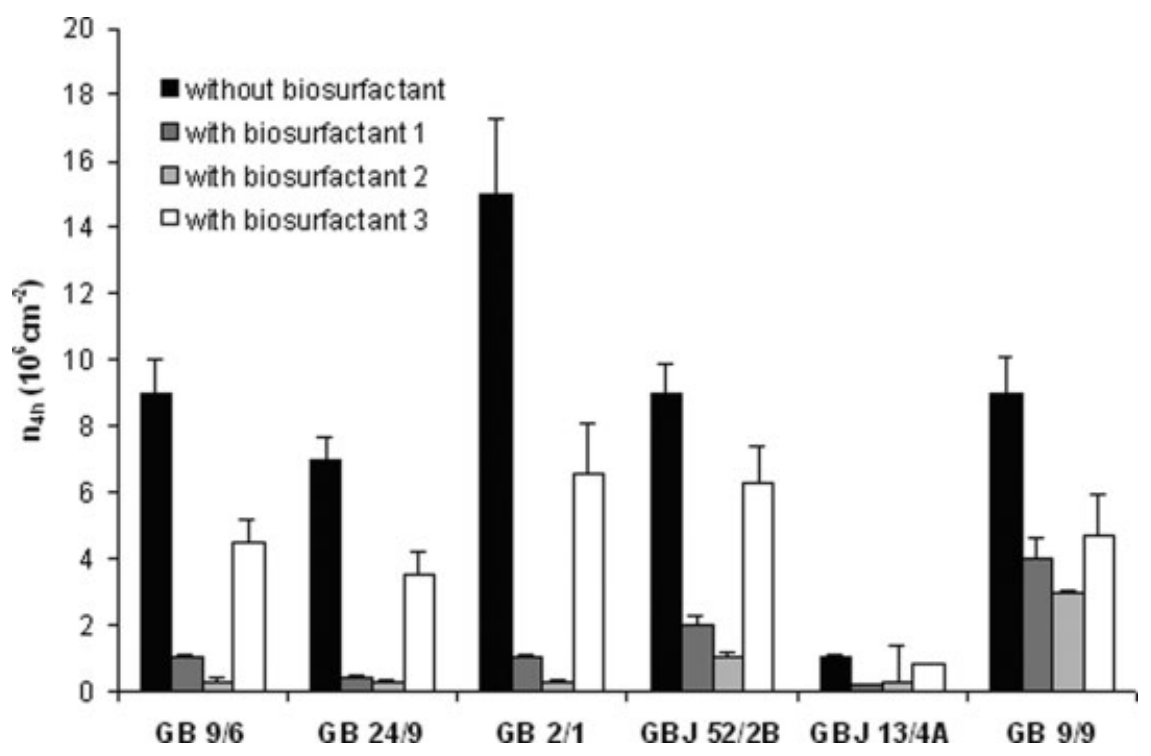

Figure 2. The number of microorganisms adhering after $4 \mathrm{~h}\left(n_{4 \mathrm{~h}}\right)$ on silicone rubber with and without an adsorbed biosurfactant layer. Biosurfactant 1,2 , and 3 were obtained from L. lactis $53, S$. thermophilus A, and $P$. aeruginosa DS10-129, respectively. The codification of the microorganisms is presented in Figure 1. Results are averages of triplicate experiments varying within 10-15\% (ANOVA) and the standard deviation represented by error bars. Adapted from Rodrigues et al. ${ }^{53,74,75}$ 


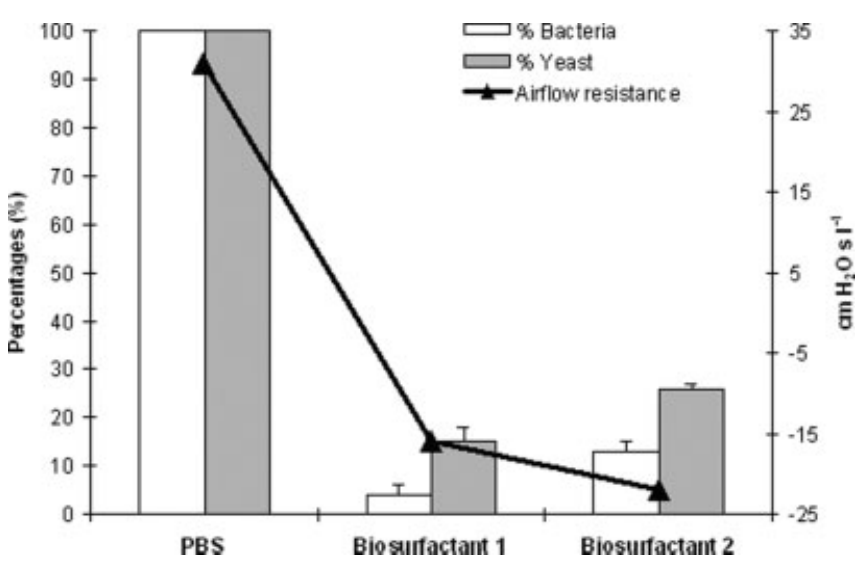

Figure 3. The percentage of viable bacteria and yeasts isolated from the voice prostheses, with and without adsorbed biosurfactants, after biofilm formation in the artificial throat. Both for bacteria and yeasts, the number of organisms found after using PBS as a control was set at $100 \%$. Also included are the decreases in airflow resistance caused by biofilms influenced by biosurfactants, compared with the effects of PBS as a control. Biosurfactant 1 was obtained from $L$. lactis 53 and biosurfactant 2 from $S$. thermophilus A. All experiments were carried out in triplicate with separately cultured strains. Adapted from Rodrigues et al. ${ }^{54}$

urogenital tract. ${ }^{71}$ Other bacterial genera known to have probiotic effects are lactococci, enterococci, and streptococci. The mechanisms by which probiotic bacteria exert their beneficial effects are not yet entirely understood. Competitive adhesion, ${ }^{77,78}$ activation of the immune system, ${ }^{79}$ and nutrient competition ${ }^{76}$ have all been suggested as such mechanisms. Some strains are able to release biosurfactants, while others are known to have antimycotic effects, produce lactic acid, or hydrogen peroxide.

Wagner et al. ${ }^{80}$ demonstrated that probiotic bacteria have biotherapeutic potential for prophylaxis and therapy against candidiasis. Free et al. $^{76}$ assessed the influence of probiotic bacteria (L. lactis 53 and S. thermophilus B) on biofilm formation on both Groningen and Provox voice prostheses in an artificial throat model. It was found that the strains affect the biofilm formation on both types of voice prostheses and increased lifetimes can be expected from carefully designed food supplements containing these bacteria. Alternatives for bacteria administration were proposed, such as freeze-dried in sachets or in a dairy product.

\section{The Effects of Dairy Products}

Several studies were carried out to assess the beneficial effect of different dairy products on the lifetime of voice prostheses, as patient support groups for laryngectomy patients have suggested that buttermilk consumption not only prolongs the clinical usefulness of indwelling silicone rubber voice prostheses but can also resolve early leakage of dysfunctioning valves. ${ }^{51,81-85}$ Busscher et al. ${ }^{81}$ simulated the consumption of buttermilk in an artificial throat model and found that it almost completely prevented biofilm formation during the experimental period. The mechanism by which the consumption of buttermilk interferes with biofilm formation can only be speculated. Buttermilk is a mildly acidic dairy product with a $\mathrm{pH}$ of 4.5 due to the presence of lactic acid produced by L. lactis and Streptococcus cremoris, and contains a number of enzymes in addition to high calcium content (110-120 mg per $100 \mathrm{~g})$. L. lactis strains are known to release antimycotic substances, while the proteins present in buttermilk include casein, lactoglobulin, and immunoglobulins, which may have detergent properties. Clearly, the combined effect of all properties of buttermilk contributes to the referred prevention of biofilm formation. Moreover, Free et al. ${ }^{85}$ demonstrated that it is feasible to formulate a dairy product based on probiotics that will strongly inhibit biofilm formation on voice prostheses.

\section{The Effects of Caffeinated Soft Drinks}

The influence of caffeinated soft drinks on biofilm formation on silicone rubber voice prostheses was also investigated in an artificial throat model $^{34}$ and a reduced bacterial prevalence in the biofilms to $1-5 \%$ of the control was observed, while yeasts thrived in the biofilms. Free et al. ${ }^{34}$ suggested caffeine or a combination of a low $\mathrm{pH}$ and high sugar content as possible causes. The relevance of the results achieved for laryngectomized patients has to be established in a clinical trial, which might be difficult because of the multiple factors influencing biofilm formation on voice prostheses in vivo.

\section{The Use of Antifungal Agents}

A strategy frequently applied by otolaryngologists to solve the rapid colonization of voice prostheses is oropharyngeal yeast decontamination by using antifungal agents, despite the fact that there is no compelling evidence that prescription of antifungal agents will prolong the lifetime of voice prostheses. Moreover, the prophylactic use of antifungal agents contributes to the development of resistant strains. Many efforts have been made to develop new antifungal drugs, as well as to clarify their effects on the lifetime of voice prostheses. ${ }^{14,25,39,86-91}$ Oropharyngeal yeast decontamination using amphotericin B lozenges and buccal adhesive slow-release tablets containing miconazole nitrate has been applied by otolaryngologists ${ }^{25,39}$ to increase the lifetime of voice prostheses. In studies ${ }^{25}$ with Groningen button voice prostheses, the successful decontamination of the oropharynx with amphotericin B lozenges $(10 \mathrm{mg}$ ) four times daily was also associated with a prolonged device life and lower airflow resistances. One of the drawbacks found in using this agent is the need for daily applications, leading to poor compliance by the patients. Bodey ${ }^{87}$ reviewed the available antifungal drugs and described new imidazoles, such as itraconazole and fluconazole. Also, liposomal preparations of amphotericin B were described as substantially less toxic and more effective, clinical trials however have yet to be carried out. Weissenbruch et al. ${ }^{39}$ conducted a double-blind randomized trial among 36 laryngectomees 
to assess the influence of a buccal bioadhesive slow-release tablet $(10 \mathrm{mg})$ containing miconazole nitrate on the lifetime of the Provox voice prosthesis. All patients colonized with Candida strains and treated with miconazole showed a significant decrease of colonization at the end of the study. The airflow resistances were remarkably higher after two months of follow-up in the placebo group. No local or systemic adverse reactions to miconazole were observed during this study. Patient compliance was acceptable according to regular miconazole determination in saliva samples. The prostheses lifetime was significantly higher in patients treated with miconazole even after one year of follow-up. The use of a buccal bioadhesive slow-release tablet containing an antimycotic agent proves to be an adequate method of preventing fungal colonization and deterioration of silicone voice prostheses.

\section{The Use of Synthetic Salivary Peptides}

Salivary dysfunction as a result of surgical therapy, radiation therapy, aging, or medication is frequently a problem for many laryngectomees. The low salivary secretion reduces the amount of histatins in saliva, yielding better chances for opportunistic microorganisms such as $C$. albicans, as histatins contains fungicidal activity. ${ }^{92}$ Artificial salivary substitutes, commonly used by xerostomic patients and sometimes by laryngectomy patients, now mainly contain carboxymethylcellulose, animal mucins, or xanthan, and such substances constitute an excellent vehicle for antifungal agents. ${ }^{93}$ Synthetic salivary peptides are promising antimicrobial agents, which can possess bactericidal and fungicidal activities. ${ }^{94}$ These salivary peptides have not so far been associated with the development of microbial resistance. Helmerhorst et al. ${ }^{94}$ reported a number of basic antifungal peptides, including human salivary histatin 5, a designed histatin analog designated dhvar4, and a peptide from frog skin, PGLa, that are active against amphotericin B-resistant C. albicans, C. krusei, and Aspergillus fumigatus strains and against a fluconazoleresistant $C$. glabrata. In addition, Elving et al. ${ }^{95}$ studied the antimicrobial activity of different synthetic salivary peptides derived from histatin against a variety of oropharyngeal microorganisms isolated from explanted voice prostheses. Designed histatin analogs designated dhvar4 and dhvar5 were the only synthetic peptides with an antimicrobial spectrum broad enough to cover the variety of oropharyngeal microorganisms found on voice prostheses.

Recently, Oosterhof et al. ${ }^{96}$ carried out experiments in an artificial throat to determine the effectiveness of dhvar4 and dhvar5 on oropharyngeal biofilm formation. The dhvar4 had no effect on mixed biofilms, while dhvar5 significanly reduced the number of both bacteria and yeasts in mixed biofilms. However, this reduction was not accompanied by a reduction in airflow resistance, suggesting that the integrity of the biofilm was not affected. This may be due to the remaining exopolysaccharide (EPS) and connecting slime threads within the biofilm, as the integrity of a biofilm is determined by the EPS matrix rather than by the number of organisms within. This was confirmed by the observation that both ascorbic acid and $N$-acetylcysteine induced similar reduction in the number of bacteria and yeasts, probably due to their antioxidant natures. Treatment with ascorbic acid did not result in a decrease in airflow resistance, whereas treatment with the mucolytic $N$-acetylcysteine did. Perez-Giraldo et al. ${ }^{97}$ studied the influence of various concentrations of $\mathrm{N}$-acetylcysteine on the formation of biofilms of different strains of $S$. epidermidis and found a dose-related decrease in biofilm and slime formation. $\mathrm{N}$ acetylcysteine, therefore, is a promising chemical to disrupt the integrity of voice prostheses biofilms, especially since it can be swallowed and used over a long period without adverse effects.

\section{CONCLUDING REMARKS}

The insertion of silicone rubber voice prostheses in a tracheoesophageal shunt is generally considered to be the main procedure for speech rehabilitation of laryngectomized patients. These implants need to be replaced when leakage through or around the prosthesis occurs, or when it becomes difficult to produce tracheoesophageal speech due to increased airflow resistance. A continuous exposure to saliva, food, drinks, and oropharyngeal microflora contribute to rapid colonization of the prostheses by biofilms of mixed bacteria and yeasts strains leading to failure and frequent replacement. Achieving an antifouling improvement for the silicone rubber material by the development of new biomaterials or new antimicrobial agents is highly desirable. This review describes the different approaches available to date and discusses future perspectives on solving the voice prostheses drawbacks. When designing new biomaterials, inhibition of microbial adhesion and growth should be achieved by changing the physicochemical properties of the biomaterial surface or by covalently binding antimicrobial agents to the biomaterial surface. Techniques used to modify silicone rubber surfaces and prophylactic treatments for silicone rubber voice prostheses have shown varying effects in the inhibition of biofilm formation and therefore in the lifetime of these prostheses. As antimicrobial resistance is a growing source of concern in modern medicine, the development of novel alternative prophylactic and therapeutic agents, including probiotics and other surface active compounds such as biosurfactants are expected to gain prominence in the future antifouling strategies.

\section{REFERENCES}

1. Singer MIM, Blom E. An endoscopic technique for restoration of voice after laryngectomy. Ann Otol Rhinol Laryngol 1980; 89:529-531.

2. Blom E. Tracheoesophageal voice restoration: Origin-evolution—state-of-the-art. Folia Phoniatr Logop 2000;52:1-3.

3. Panje WR. Prosthetic vocal rehabilitation following laryngectomy. Ann Otol Rhinol Laryngol 1981;90:116-120. 
4. Nijdam HF, Annyas AA, Schutte HK, Leever H. A new prosthesis for voice rehabilitation after laryngectomy. Arch Otorhinolaryngol 1982;237:27-29.

5. Traissac L, Devars F, Gioux M, Petit J, Benjebria A, Henry CH, Ucelay I. La réhabilitation vocale du laryngectomisé par implant phonatoire. Rev Laryngol 1987;108:157-159.

6. Nijdam HF, Manni JJ, Nicolasen M. A new valveless lowpressure voice prostheses. Clin Otolaryngol 1990;15:561.

7. Hilgers FJM, Schouwenburg PF. A new low-resistance, selfretaining prosthesis $\left(\right.$ Provox $^{\circledR}$ ) for voice rehabilitation after total laryngectomy. Laryngoscope 1990;100:1202-1207.

8. Staffieri M, Staffieri A. A new voice button for post-total laryngectomy speech rehabilitation. Laryngoscope 1988;98:10271029.

9. Hilgers FJM, Cornelissen MW, Balm AJM. Aerodynamic characteristics of the low-resistance, indwelling Provox ${ }^{\circledR}$ voice prosthesis. Eur Arch Otorhinolaryngol 1993;250:375-380.

10. Van den Hoogen F, Oudes M, Hombergen G, Nijdam H, Manni J. The Groningen, Nijdam and Provox Voice prostheses: A prospective clinical comparison based on 845 replacements. Acta Otolaryngol 1996;116:119-124.

11. Van Lith-Bijl J, Mahieu H, Patel P, Zijlstra R. Clinical experience with the low-resistance Groningen button. Eur Arch Otorhinolaryngol 1992;249:354-357.

12. Laccourreye O, Menard M, Crevier-Buchman L, Couloigner V, Brasnu D. In situ lifetime, causes for replacement, and complications of the Provox voice prosthesis. Laryngoscope 1997; 107:527-530.

13. Leunisse C, Van Weissenbruch R, Busscher HJ, Van der Mei HC, Dijk F, Albers FWJ. Biofilm formation and design features of indwelling silicone rubber tracheoesophageal voice prostheses-An electron microscopical study. J Biomed Mater Res 2001;58:556-563.

14. Ackerstaff A, Hilgers F, Meeuwis C, Van der Velden L, Van den Hoogen F, Marres H, Vreeburg G, Manni J. Multi-institutional assessment of the Provox 2 voice prosthesis. Arch Otolaryngol Head Neck Surg 1999;125:167-173.

15. Hoght AH, Dankert J, Feijen J. Adhesion of coagulase-negative staphylococci to methacrylate polymers and copolymers. J Biomed Mater Res 1986;20:533-545.

16. Keogh JR, Eaton JW. Albumin binding surfaces for biomaterials. J Lab Clin Med 1994;124:537-545.

17. Van de Belt H, Neut D, Uges DRA, Schenk W, Van Horn JR, Van der Mei HC, Busscher HJ. Surface roughness, porosity and wettability of gentamicin-loaded bone cements and their antibiotic release. Biomaterials 2000;21:1981-1987.

18. Douglas L. Candida biofilms and their role in infection. Trends Microbiol 2003;11:30-36.

19. Flemming RG, Capelli CC, Cooper SL, Proctor RA. Bacterial colonization of functionalized polyurethanes. Biomaterials 2000;21:273-281.

20. Gottenbos B, Van der Mei HC, Klatter F, Nieuwenhuis P, Busscher HJ. In vitro and in vivo antimicrobial activity of covalently coupled quaternary ammonium silane coatings on silicone rubber. Biomaterials 2002;23:1417-1423.

21. Gottenbos B, Busscher HJ, Van der Mei HC. Pathogenesis and prevention of biomaterial centered infections. J Mater Sci Mater Med 2002;13:717-722.

22. Press RI, Peebles CL, Kumagai Y, Ochs RL, Tan EM. Antinuclear auto-antibodies in woman with silicone breast implants. Lancet 1992;340:1304-1307.

23. Neu T, Dijk F, Verkerke G, Van der Mei HC, Busscher HJ. Scanning electron microscopy study of biofilms on silicone voice prostheses. Cells Mater 1992;2:261-269.

24. Neu T, Van der Mei HC, Busscher HJ, Dijk F, Verkerke G. Biodeterioration of medical-grade silicone rubber used for voice prostheses: A SEM study. Biomaterials 1993;14:459_ 464.
25. Mahieu H, Van Saene H, Rosingh H, Schutte H. Candida vegetations on silicone voice prostheses. Arch Otolaryngol Head Neck Surg 1986;112:321-325.

26. Palmer M, Johnson A, Elliott T. Microbial colonization of Blom-Singer prostheses in postlaryngectomy patients. Laryngoscope 1993;103:910-914.

27. Neu T, Verkerke G, Herrmann I, Schutte H, Van der Mei HC, Busscher HJ. Microflora on explanted silicone rubber voice prostheses: Taxonomy, hydrophobicity and electrophorectic mobility. J Appl Bacteriol 1994;76:521-528.

28. Neu T, De Boer C, Verkerke G, Schutte H, Rakhorst G, Van der Mei HC, Busscher HJ. Biofilm development in time on a silicone voice prosthesis-A case study. Microb Ecol Health Dis 1994;7:27-33.

29. Everaert E, Mahieu H, Chung R, Verkerke G, Van der Mei $\mathrm{HC}$, Busscher HJ. A new method for in vivo evaluation of biofilms on surface-modified silicone rubber voice prostheses. Eur Arch Otorhinolaryngol 1997;254:261-263.

30. Van Weissenbruch R, Albers FWJ, Bouckaert S, Nelis H, Criel G, Remon J, Sulter A. Deterioration of the Provox silicone tracheoesophageal voice prosthesis: Microbial aspects and structural changes. Acta Otolaryngol (Stockh) 1997;117:452-458.

31. Van der Mei HC, Van de Belt-Gritter B, Dijk F, Busscher HJ. Initial deterioration of silicone rubber by Candida albicans and Candida tropicalis strains isolated from voice prostheses. Cells Mater 1996;6:157-163.

32. Ell SR, Davies CM, Clegg RT, Parker AJ. Do bacteria play a role in silastic speaking valve failure? In: Algaba J, editor. Surgery and Prosthetic Voice Restoration After Total and Subtotal Laryngectomy. Amsterdam: Elsevier Science; 1996. pp 363-365.

33. Eerenstein S, Grolman W, Schouwenburg P. Microbial colonization of silicone rubber voice prostheses used in laryngectomized patients. Clin Otolaryngol 1999;24:398-403.

34. Free RH, Elving G, Van der Mei HC, Van Weissenbruch R, Albers FWJ, Busscher HJ. Caffeinated soft drinks reduce bacterial prevalence in voice prosthetic biofilms. Biofouling 2000;16: 69-76.

35. Millsap K, Bos R, Van der Mei HC, Busscher HJ. Adhesive interactions between voice prosthetic yeast and bacteria on silicone rubber in the absence and presence of saliva. Antonie Van Leeuwenhoek 2001;79:337-343.

36. Elving G, Van der Mei HC, Busscher HJ, Van Weissenbruch R, Albers FWJ. Air-flow resistances of silicone rubber voice prosthesis after formation of bacterial and fungal biofilms. J Biomed Mater Res 2001;58:421-426.

37. Elving GJ, Van der Mei HC, Busscher HJ, Van Weissenbruch $\mathrm{R}$, Albers FW. Comparison of the microbial composition of voice prosthesis biofilms from patients requiring frequent versus infrequent replacement. Ann Otol Rhinol Laryngol 2002;111: 200-203.

38. Foley I, Gilbert P. Antibiotic resistance of biofilms. Biofouling 1996;10:331-346.

39. Van Weissenbruch R, Bouckaert S, Remon J. Chemoprophylaxis of fungal deterioration of the Provox silicone tracheoesophageal prosthesis in postlaryngectomy patients. Ann Otol Rhinol Laryngol 1997;106:329-337.

40. Busscher HJ, Cowan MM, Van der Mei HC. On the relative importance of specific and non-specific approaches to oral microbial adhesion. FEMS Microbiol Lett 1992;88:199-210.

41. Busscher HJ, Geertsema-Doornbusch GI, Van der Mei HC. Adhesion to silicone rubber of yeasts and bacteria isolated from voice prostheses: Influence of salivary conditioning films. J Biomed Mater Res 1997;34:201-210.

42. Arweiler-Harbeck D, Sanders A, Held M, Jerman M, Ehrich $\mathrm{H}$, Jahnke K. Does metal coating improve the durability of silicone rubber voice prosthesis? Acta Otolaryngol 2001;121: 643-646. 
43. Balazs D, Triandafillu K, Wood P, Chevolot Y, Van Delden C, Harms H, Hollenstein C, Mathieu H. Inhibition of bacterial adhesion on PVC endotracheal tubes by RF-oxygen glow discharge, sodium hydroxide and silver nitrate treatments. Biomaterials 2004;25:2139-2151.

44. Dijk F, Westerhof M, Busscher HJ, Van Luyn M, Van der Mei HC. In vitro formation of oropharyngeal biofilms on silicone rubber treated with a palladium/tin salt mixture. J Biomed Mater Res 2000;51:408-412.

45. Everaert E, Mahieu H, Reitsma A, Van de Belt-Gritter B, Van der Mei HC, Verkerke G, Busscher HJ. In vitro and in vivo microbial adhesion and growth on argon plasma treated silicone rubber voice prostheses. J Mater Sci Mater Med 1998;9: 147-157.

46. Everaert E, Mahieu H, Van de Belt-Gritter B, Peeters J, Verkerke G, Van der Mei HC, Busscher HJ. Biofilm formation in vivo on perfluoro-alkylsiloxane-modified voice prostheses. Arch Otolaryngol Head Neck Surg 1999;125:1329-1332.

47. Everaert E, Van der Mei HC, Busscher HJ. Adhesion of yeasts and bacteria to fluoro-alkylsiloxane layers chemisorbed on silicone rubber. Colloids Surf B Biointerfaces 1998;10: 179-190.

48. Angelova N, Hunkeler D. Rationalizing the design of polymeric biomaterials. Trends Biotechnol 1999;17:409-421.

49. Abbasi F, Mirzadeh H, Katbab A. Bulk and surface modification of silicone rubber for biomedical applications. Polym Int 2002;51:882-888.

50. Ramakrishnan A, Dhamodharan R, Ruhe J. Controlled growth of PMMA brushes on silicon surfaces at room temperature. Macromol Rapid Commun 2002;23:612-616.

51. Busscher HJ, Mulder A, Van der Mei HC. In vitro adhesion to enamel and in vivo colonization of tooth surfaces by lactobacilli from a bio-yoghurt. Caries Res 1999;33:403,404.

52. Busscher HJ, Van de Belt-Gritter B, Westerhof M, Van Weissenbruch R, Albers FWJ, Van der Mei HC. Microbial interference in the colonization of silicone rubber implant surfaces in the oropharynx: Streptococcus thermophilus against a mixed fungal/bacterial biofilm. In: Rosenberg E, editor. Microbial Ecology and Infectious Disease. Washington D.C.: American Society for Microbiology; 1999. pp 66-74.

53. Rodrigues LR, Van der Mei HC, Teixeira J, Oliveira R. Biosurfactant from Lactococcus lactis 53 inhibit microbial adhesion on silicone rubber. Appl Microbiol Biotechnol 2004;66: 306-311.

54. Rodrigues LR, Van der Mei HC, Teixeira J, Oliveira R. Influence of biosurfactants from probiotic bacteria on formation of biofilms on voice prostheses. Appl Environ Microbiol 2004; 70:4408-4410.

55. Quirynen M, Bollen CM. The influence of surface roughness and surface-free energy on supra- and subgingival plaque formation in man. A review of the literature. J Clin Periodontol 1995;22:1-14.

56. Quirynen M, Marechal M, Busscher HJ, Weerkamp A, Arends J, Darius P, Van Steenberghe D. The influence of surface free-energy on planimetric plaque growth in man. J Dent Res 1989;68:796-799.

57. Gottenbos B, Grijpma D, Van der Mei HC, Feijen J, Busscher HJ. Antimicrobial effects of positively charged surfaces on adhering Gram-positive and Gram-negative bacteria. J Antimicrob Chemother 2001;48:7-13.

58. Kenawy E, Abdel-Hay FI, El-Shanshoury AR, El-Newehy MH. Biologically active polymers: Synthesis and antimicrobial activity of modified glycidyl methacrylate polymers having a quaternary ammonium and phosphonium groups. J Control Release 1998; 50:145-152.

59. Rodrigues LR, Banat IM, Teixeira JA, Oliveira R. Biosurfactants: Potential applications in medicine. J Antimicrob Chemother 2006;57:609-618.
60. Banat IM, Makkar RS, Cameotra SS. Potential commercial applications of microbial surfactants. Appl Microbiol Biotechnol 2000;53:495-508.

61. Banat IM. Biosurfactants production and possible uses in microbial enhanced oil recovery and oil pollution remediation: A review. Bioresource Technol 1995;51:1-12.

62. Banat IM, Samarah N, Murad M, Horne R, Banerjee S. Biosurfactant production and use in oil tank clean-up. World J Microbiol Biotechnol 1991;7:80-88.

63. Banat IM. Characterization of biosurfactants and their use in pollution removal-State of the art (Review). Acta Biotechnol. 1995;15:251-267.

64. Neu T. Significance of bacterial surface active compounds in interaction of bacteria with interfaces. Microbiol Rev 1996;60: 151-166.

65. Pratt-Terpstra IH, Weerkamp AH, Busscher HJ. Microbial factors in a thermodynamic approach of oral streptococcal adhesion to solid substrata. J Colloid Interface Sci 1989;129: $568-574$.

66. Van Hoogmoed CG, Van der Kuijl-Booij M, Van der Mei $\mathrm{HC}$, Busscher HJ. Inhibition of Streptococcus mutans NS adhesion to glass with and without a salivary conditioning film by biosurfactant-releasing Streptococcus mitis strain. Appl Environ Microbiol 2000;66:659-663.

67. Velraeds M, Van der Mei HC, Reid G, Busscher HJ. Inhibition of initial adhesion of uropathogenic Enterococcus faecalis by biosurfactants from Lactobacillus isolates. Appl Environ Microbiol 1996;62:1958-1963.

68. Reid G, Tieszer C, Foerch R, Busscher HJ, Khoury AE, Van der Mei HC. The binding of urinary components and uropathogens to a silicone latex urethral catheter. Cells Mater 1992;2: 253-260.

69. Reid G, Bruce A, Smeianov V. The role of Lactobacilli in preventing urogenital and intestinal infections. Int Dairy J 1998; $8: 555-562$.

70. Reid G, Heinemann C, Velraeds M, Van der Mei HC, Busscher HJ. Biosurfactants produced by Lactobacillus. Methods Enzymol 1999;310:426-433.

71. Reid G, Zalai C, Gardiner G. Urogenital Lactobacilli probiotics, reliability, and regulatory issues. J Dairy Sci 1984;84E: 164-169.

72. Velraeds M, Van de Belt-Gritter B, Van der Mei HC, Reid G, Busscher HJ. Interference in initial adhesion of uropathogenic bacteria and yeasts to silicone rubber by a Lactobacillus acidophilus biosurfactant. J Med Microbiol 1998;47:1081-1085.

73. Busscher HJ, Neu T, Van der Mei HC. Biosurfactant production by thermophilic dairy streptococci. Appl Microbiol Biotechnol 1994;41:4-7.

74. Rodrigues LR, Van der Mei HC, Banat IM, Teixeira JA, Oliveira $\mathrm{R}$. Inhibition of microbial adhesion to silicone rubber treated with biosurfactant from Streptococcus thermophilus A. FEMS Immunol Med Microbiol 2006;46:107-112.

75. Rodrigues LR, Banat IM, Van der Mei HC, Teixeira JA, Oliveira $R$. Interference in adhesion of bacteria and yeasts isolated from explanted voice prostheses to silicone rubber by rhamnolipid biosurfactant. J Appl Microbiol 2006;100:470-480.

76. Free RH, Van der Mei HC, Dijk F, Van Weissenbruch R, Busscher HJ, Albers FWJ. Biofilm formation on voice prostheses: In vitro influence of probiotics. Ann Otol Rhinol Laryngol 2001;110:946-951.

77. Batish V, Lal R, Chander H. Effect of nutritional factors on the production of antifungal substance by Lactococcus lactis subsp. lactis biovar diacetylactis. Aust J Dairy Technol 1990;45: 74-76.

78. Busscher HJ, Van Hoogmoed CG, Geertsema-Doornbusch GI, Van der Kuijl-Booij M, Van der Mei HC. Streptococcus thermophilus and its biosurfactants inhibit adhesion by Candida spp. on silicone rubber. Appl Environ Microbiol 1997;63:3810-3817. 
79. Perdigon G, De Marcias ME, Alvaraz S, Oliver G, De RuizHolgado AA. Effect of perorally administrated lactobacilli on macrophage activation in mice Infect Immun 1986;53:404-410.

80. Wagner R, Pierson C, Warner T, Dohnalek M, Farmer J, Roberts L, Hilty M, Balish E. Biotherapeutic effects of probiotic bacteria on candidiasis in immunodeficient mice. Infect Immun 1997;65:4165-4172.

81. Busscher HJ, Bruinsma G, Van Weissenbruch R, Leunisse C, Van der Mei HC, Dijk F, Albers FWJ. The effect of buttermilk consumption on biofilm formation on silicone rubber voice prostheses in an artificial throat. Eur Arch Otorhinolaryngol 1998;255:410-413.

82. Busscher HJ, Free RH, Van Weissenbruch R, Albers FWJ, Van der Mei HC. Preliminary observations on influence of dairy products on biofilm removal from silicone rubber voice orostheses in vitro. J Dairy Sci 2000;83:641-647.

83. Van der Mei HC, Van de Belt-Gritter B, Van Weissenbruch R, Dijk F, Albers FWJ, Busscher HJ. Effect of the consumption of dairy products with probiotic bacteria on biofilm formation on silicone rubber implant surfaces in an artificial throat. Trans IChemE 1999;77C:156-158.

84. Van der Mei HC, Free RH, Elving GJ, Van Weissenbruch R, Albers FWJ, Busscher HJ. Effect of probiotic bacteria on prevalence of yeasts in oropharyngeal biofilms on silicone rubber voice prostheses in vitro. J Med Microbiol 2000;49:713-718.

85. Free RH, Elving G, Van Weissenbruch R, Busscher HJ, Van der Mei HC, Albers FWJ. Biofilm formation on voice prostheses: Influence of dairy products in vitro. Acta Otolaryngol 2000;120:92-99.

86. Graybill J. Systemic antifungal drugs. Rev Iberoam Micol 2000; 17:168-174.

87. Bodey G. Topical and systemic antifungal agents Med Clin North Am 1988;72:637-659.
88. Georgopapadakou N, Walsh T. Antifungal agents: Chemotherapeutic targets and immunologic strategies. Antimicrob Agents Chemother 1996;40:279-291.

89. Sheehan D, Hitchcock C, Sibley C. Current and emerging azole antifungal agents. Clin Microbiol Rev 1999;12:40-79.

90. Andriole V. Current and future antifungal therapy: New targets for antifungal agents. J Antimicrob Chemother 1999;44: 151-162.

91. Bauters T, Moerman M, Vermeersch H, Nelis H. Colonization of voice prostheses by Albicans and non-albicans Candida species. Laryngoscope 2002;112:708-712.

92. Tenovuo J. Antimicrobial function of human saliva-How important is it for oral health? Acta Odontol Scand 1998;56:250-256.

93. Ruissen A, Van der Reijden W, Van't Hof W, Veerman E, Amerongen A. Evaluation of the use of xanthan as vehicle for cationic anfifungal peptides. J Control Release 1999;60:49-56.

94. Helmerhorst E, Reijnders I, Van't Hof W, Simoons-Smit I, Veerman E, Amerongen A. Amphotericin B- and Fluconazoleresistant Candida spp. Aspergillus fumigatus, and other newly emerging pathogenic fungi are susceptible to basic antifungal peptides. Antimicrob Agents Chemother 1999;43:702-704.

95. Elving G, Van der Mei HC, Busscher HJ, Amerongen A, Veerman E. Antimicrobial activity of synthetic salivary peptides against voice prosthetic microrganisms. Laryngoscope 2000;110:321-324.

96. Oosterhof J, Elving G, Stokroos I, Amerongen A, Van der Mei HC, Busscher HJ, Van Weissenbruch R, Albers FWJ. The influence of antimicrobial peptides and mucolytics on the integrity og biofilms consisting of bacteria and yeasts as affecting voice prosthesis air flow resistances. Biofouling 2003; 19:347-353.

97. Perez-Giraldo C, Rodriguez-Benito A, Moran FJ, Hurtado C, Blanco MT, Gomez-Garcia AC. Influence of N-acetylcysteine on the formation of biofilm by Staphylococcus epidermidis. J Antimicrob Chemother 1997;39:643-646. 